Article

\title{
Titanium Dioxide Nanoparticle Humidity Microsensors Integrated with Circuitry on-a-Chip
}

\section{Yu-Chih Hu ${ }^{1}$, Ching-Liang Dai ${ }^{1}{ }^{*}$ and Cheng-Chih Hsu ${ }^{2}$}

1 Department of Mechanical Engineering, National Chung Hsing University, Taichung 402, Taiwan;

E-Mail: willy06101024@yahoo.com.tw

2 Department of Electro-Optical Engineering, Yuan Ze University, Taoyuan 320, Taiwan;

E-Mail: cchsu@saturn.yzu.edu.tw

* Author to whom correspondence should be addressed; E-Mail: cldai@ dragon.nchu.edu.tw;

Tel.: +886-4-2284-0433; Fax: +886-4-2287-7170.

Received: 28 December 2013; in revised form: 13 February 2014 / Accepted: 26 February 2014 /

Published: 3 March 2014

\begin{abstract}
A humidity microsensor integrated with a readout circuit on-a-chip fabricated using the commercial $0.18 \mu \mathrm{m}$ CMOS (complementary metal oxide semiconductor) process was presented. The integrated sensor chip consists of a humidity sensor and a readout circuit. The humidity sensor is composed of a sensitive film and interdigitated electrodes. The sensitive film is titanium dioxide prepared by the sol-gel method. The titanium dioxide is coated on the interdigitated electrodes. The humidity sensor requires a post-process to remove the sacrificial layer and to coat the titanium dioxide. The resistance of the sensor changes as the sensitive film absorbs or desorbs vapor. The readout circuit is employed to convert the resistance variation of the sensor into the output voltage. The experimental results show that the integrated humidity sensor has a sensitivity of $4.5 \mathrm{mV} / \mathrm{RH} \%$ (relative humidity) at room temperature.
\end{abstract}

Keywords: integrtaed humidity microsensor; titanium dioxide; readout circuit

\section{Introduction}

Humidity sensors are important devices for application in industrial and electronic equipment. Various traditional sensors have been miniaturized as microsensors using micromachining technology. Micromachined sensors have the benefits of high performance, low cost, small size, and easy 
mass-production [1]. Many humidity microsensors have been manufactured using micromachining technology. For instance, Chen et al. [2] used micromachining technology to fabricate a capacitive relative humidity sensor in which its sensitive material was zinc oxide. The humidity-sensitive $\mathrm{ZnO}$ nanorods were synthesized by the thermal decomposition, and then deposited on the micromachined electrodes by dielectrophoretic manipulation. Kim et al. [3] developed a capacitive humidity sensor using microelectromechanical system (MEMS) technology. The structure of the humidity sensor was composed of interdigitated electrodes and a polyimide sensing layer. The height of interdigitated electrodes was increased in order to enhance the capacitance and sensitivity of the sensor, and it had a sensitivity of $37.1 \mathrm{fF} / \mathrm{RH} \%$ (relative humidity). Lee et al. [4] presented an integrated humidity sensor with micropumps. The valve-less micropumps in the sensor system were fabricated using micromachining process of a deep reactive ion etching and an anodic bonding step. The maximum flow rate of the micropumps was $0.176 \mu \mathrm{L} / \mathrm{min}$. The sensitivity of the humidity sensor with pumping was 10 times higher than it was without pumping. Lee et al. [5] manufactured a novel high-speed polyimide-based humidity sensor using a combination of isotropic and anisotropic etching steps with inductively coupled plasma and a localized curing of polyimide film on microhotplate. The polyimide capacitive humidity sensor showed a sensitivity of $0.77 \mathrm{pF} / \mathrm{RH} \%$. Chen et al. [6] proposed a humidity microsensor with a micromachined silicon dioxide cantilever beam. The fabrication of the sensor combined the isotropic and anisotropic dry etching of inductively couple plasma to release the silicon dioxide cantilever beam. Deflection amplitude of the silicon dioxide microcantilever beam was observed upon exposure to $1 \%$ relative humidity. Su et al. [7] employed MEMS technology and thick-film technology to make a resistive humidity microsensor. The microsensor consisted of a suspended planar membrane, metal electrodes and a humidity-sensing film. Metal electrodes were located on the surface of the membrane, and the humidity-sensing film of poly-[3-(methacryloylamino)propyl] trimethylammonium chloride and $\mathrm{SiO}_{2}$ was coated on the top of the electrodes. The conductivity of the humidity-sensing film changed upon adsorption/desorption of water vapor. Lazarus and Fedder [8] fabricated a capacitive humidity microsensor using complementary metal oxide semiconductor (CMOS)-MEMS technique. The fabrication of the microsensor included adding oxide pillars to hold the plate apart, spin coating polymer to the electrodes, adding a polysilicon heater and etching away excess polymer in the release holes. The humidity sensor had a sensitivity of $0.21 \%$ change in capacitance per $\mathrm{RH} \%$. A capacitive humidity microsensor, proposed by Zhao et al. [9], was fabricated using the CMOS process. The microsensor was composed of a polysilicon heater, aluminum interdigitated electrodes and a humidity-sensing film of polyimide. Both the hysteresis and the recovery time of the sensor were improved based on the polysilicon heater. Yang et al. [10] utilized the commercial CMOS process to produce a resistive humidity microsensor. The sensitive film of the sensor was polyaniline doping polyvinyl alcohol (PVA) prepared by sol-gel method. The sensitivity of the humidity sensor was $12.6 \mathrm{k} \Omega / \mathrm{RH} \%$. The humidity microsensors [2-10] were not integrated with circuitry on-a-chip. Microsensors integrated with circuitry on-a-chip have the benefits of low package cost and high performance [1]. In this work, we manufacture a humidity sensor integrated with a readout circuit on chip.

The commercial CMOS process has been used to develop various microsensors and microactuators [11-14]. Microsensors fabricated by this process can be integrated with circuitry on-a-chip [15-18]. In this study, a humidity sensor with a readout circuit on chip is manufactured 
using the CMOS process. Titanium dioxide prepared by the sol-gel method is adopted as the sensitive material of the sensor. The sensor needs a post-process [19-21] to coat the sensitive material. The post-process contains etching the sacrificial oxide layer and depositing the sensitive film.

\section{Structure of the Humidity Sensor}

Figure 1 illustrates the schematic structure of the integrated humidity sensor chip. The integrated microsensor chip consists of a humidity sensor and a readout circuit. The humidity sensor is composed of interdigitated electrodes and a sensitive film. The interdigitated electrodes are $300 \mu \mathrm{m}$ long and $6 \mu \mathrm{m}$ thick, and their widths are both 5 and $10 \mu \mathrm{m}$. The gap between the interdigitated electrodes is $10 \mu \mathrm{m}$. Material of the sensitive film is titanium dioxide, and the sensitive film is coated on the interdigitated electrodes. When the sensitive film of titanium dioxide adsorbs vapor, the conductivity of the film increases because the electrons in the film increases, leading to the resistance of the film decreases $[22,23]$. Thereby, the humidity sensor is a resistive type. The humidity sensor produces a change in resistance when the sensitive film adsorbs or desorbs vapor.

Figure 1. Schematic structure of the integrated humidity sensor.

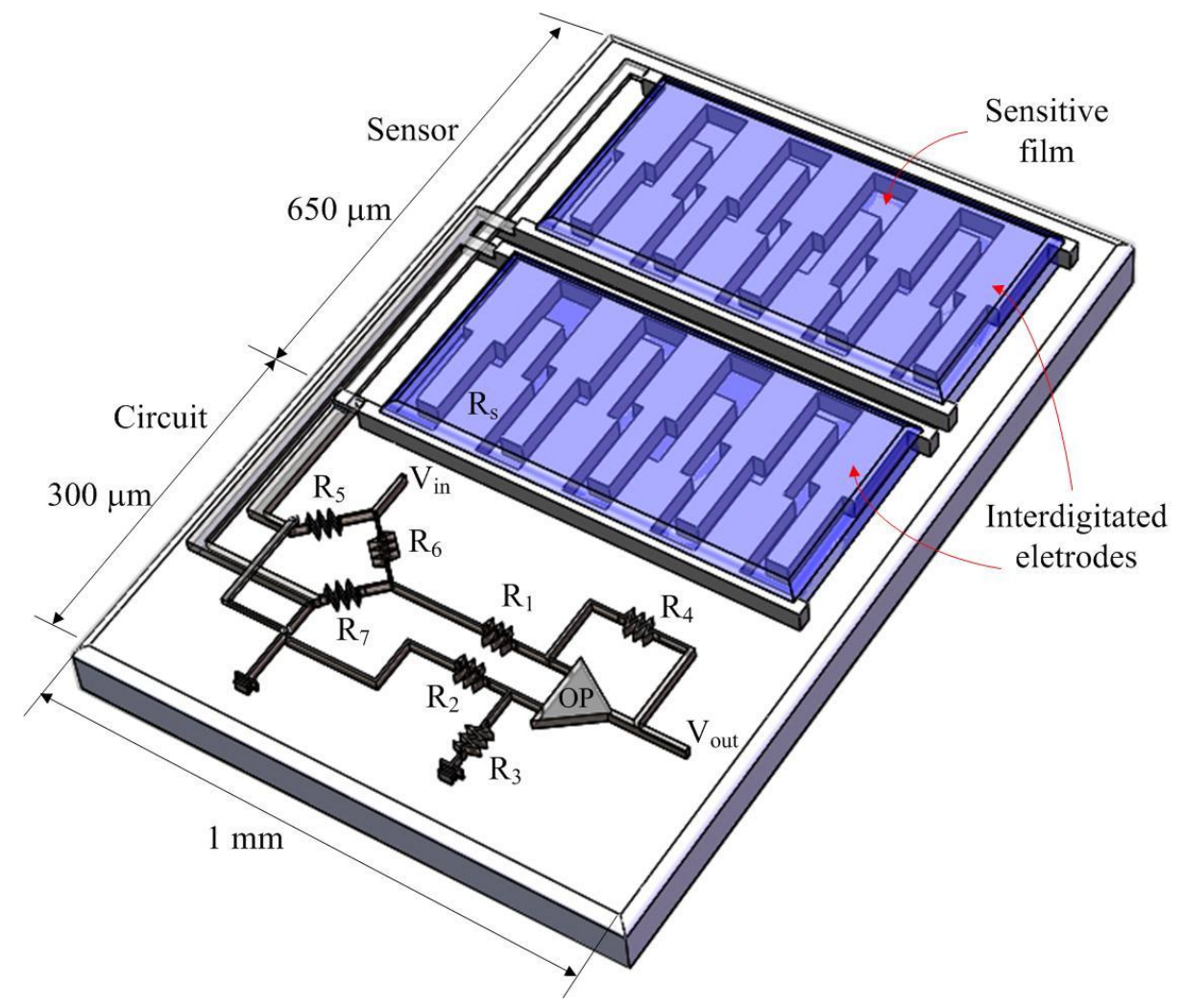

As shown in Figure 1, the integrated microsensor contains a readout circuit [24] to convert the resistance variation of the humidity sensor into the output voltage, where $O P$ represents the operational amplifier, $V_{\text {in }}$ is the input voltage of the circuit; $V_{\text {out }}$ is the output voltage of the circuit; $R_{\mathrm{s}}$ is the resistance of the humidity sensor; $R_{1}-R_{7}$ are the resistances of the circuit.

The software HSPICE (Synopsys Taiwan Co., Ltd., Hsinchu, Taiwan) is utilized to simulate the characteristics of the readout circuit. Figure 2 shows the simulated results of output voltage for the readout circuit. In this simulation, the resistances $R_{1}=5 \mathrm{k} \Omega, R_{2}=5 \mathrm{k} \Omega, R_{3}=30 \mathrm{k} \Omega, R_{4}=30 \mathrm{k} \Omega$, 
$R_{5}=20 \mathrm{k} \Omega, R_{6}=30 \mathrm{k} \Omega, R_{7}=10 \mathrm{k} \Omega$ and $R_{\mathrm{s}}=100 \mathrm{k} \Omega$ are set, and the input voltage $V_{\text {in }}$ is $2.5 \mathrm{~V}$. The bias voltage of the amplifier is $3.3 \mathrm{~V}$. The resistance of the humidity sensor varies from 400 to $100 \mathrm{k} \Omega$. The simulated results revealed that the output voltage of the readout circuit decreased from 2.39 to $2.14 \mathrm{~V}$ as the resistance of the sensor changed from 400 to $100 \mathrm{k} \Omega$. To characterize the relation between the output voltage and temperature for the readout circuit, the readout circuit is simulated at different temperatures. Figure 3 shows the simulated results of output voltage for the readout circuit at different temperatures. In this investigation, the bias voltage of the amplifier is $3.3 \mathrm{~V}$, and the input voltage $V_{\text {in }}$ is $2.5 \mathrm{~V}$. The resistance of the humidity sensor is $120 \mathrm{k} \Omega$, and the resistances are $R_{1}=5 \mathrm{k} \Omega$, $R_{2}=5 \mathrm{k} \Omega, R_{3}=30 \mathrm{k} \Omega, R_{4}=30 \mathrm{k} \Omega, R_{5}=20 \mathrm{k} \Omega, R_{6}=30 \mathrm{k} \Omega$ and $R_{7}=10 \mathrm{k} \Omega$. The temperature changes from 20 to $80{ }^{\circ} \mathrm{C}$. The results showed that the output voltage of the readout circuit increased from 2.1485 to $2.1491 \mathrm{~V}$ as the temperature changes from 20 to $80{ }^{\circ} \mathrm{C}$, in which the output voltage varies about $0.6 \mathrm{mV}$.

Figure 2. Simulated results of the output voltage for the readout circuit.

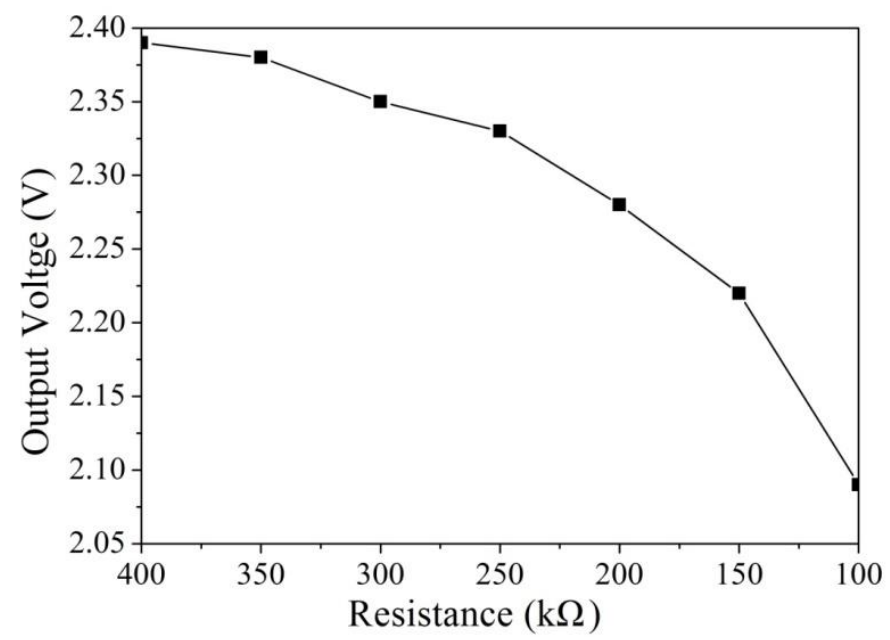

Figure 3. Relation between output voltage and temperature for the circuit.

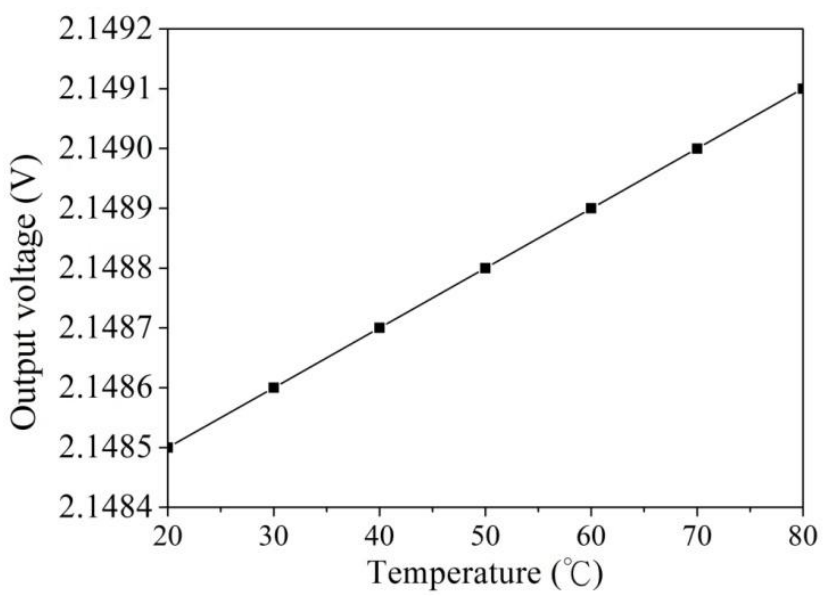

\section{Preparation of the Sensitive Film}

The sensitive film of the humidity sensor was titanium dioxide prepared by the sol-gel method $[25,26]$. The titanium dioxide was prepared as follows: titanium isopropoxide $\left(\mathrm{Ti}\left(\mathrm{OC}_{3} \mathrm{H}_{7}\right)_{4}\right)$ 
precursor of $3 \mathrm{~mL}$ (Henan Tianfu Chemical Co., Henan, China) was dissolved in isopropanol $\left(\mathrm{C}_{3} \mathrm{H}_{8} \mathrm{O}\right.$, $20 \mathrm{~mL}$ ) (Rhett Chemical Co., Taipei, Taiwan) with stirring for $30 \mathrm{~min}$ until the solution was mixed uniformly. Deionized water $(40 \mathrm{~mL})$ was added into the mixed solution with stirring for $1 \mathrm{~h}$. Then, $\mathrm{HNO}_{3}$ solution of $5 \mathrm{~mL}$ (Kaomu Co., Kaohsiung, Taiwan) was added into the mixed solution and stirred for $20 \mathrm{~min}$, followed by aging for $30 \mathrm{~min}$. The slurry of titanium dioxide was filtered, and then rinsed with deionized water. Finally, the titanium dioxide was coated on the substrate with calcinations at $400{ }^{\circ} \mathrm{C}$ for $1 \mathrm{~h}$.

Scanning electron microscopy (SEM, JEOL JSM-6700F, Tokyo, Japan) was used to measure the surface morphology of the titanium dioxide film. Figure 4 presents a SEM image of titanium dioxide film. The film was nanoparticle structures that have a large surface area and helps to enhance its sensitivity. The energy dispersive spectrometer (EDS) was employed to test the composition of the titanium dioxide film. Figure 5 shows an EDS analysis of the titanium dioxide, where the main elements are titanium and oxygen. The results showed that the titanium dioxide film contained titanium of $50.75 \mathrm{wt} \%$ and oxygen of $49.25 \mathrm{wt} \%$.

Figure 4. SEM image of the titanium dioxide film.

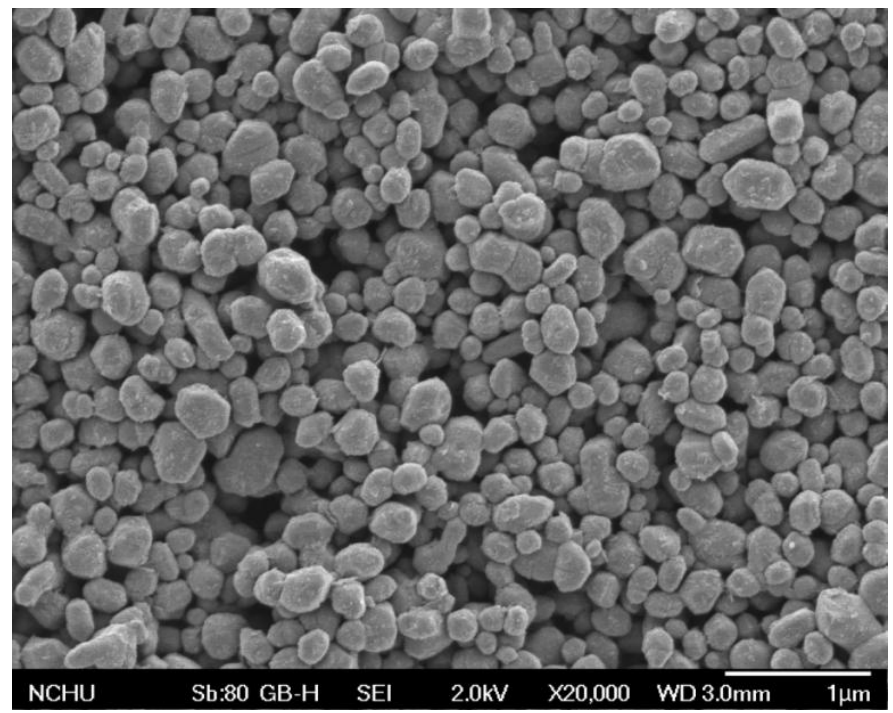

Figure 5. EDS analysis of the titanium dioxide film.

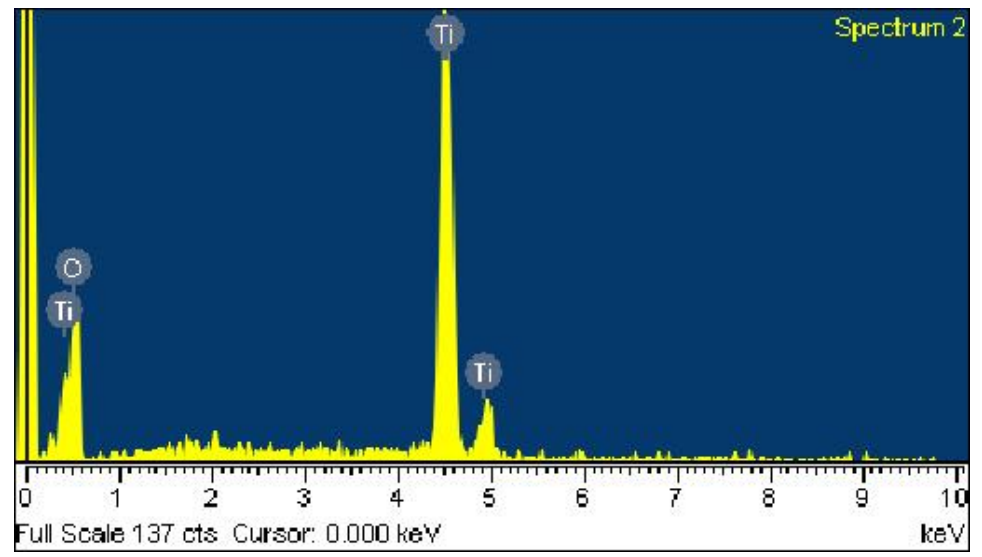




\section{Fabrication of the Humidity Sensor}

The commercial 0.18 $\mu \mathrm{m}$ CMOS process of Taiwan Semiconductor Manufacturing Company (TSMC, Taipei, Taiwan) was employed to manufacture the integrated humidity sensor chip. Figure 6 shows the fabrication flow of the integrated humidity sensor. The humidity sensor needed a post-process [27] to coat the sensitive film after completion of the CMOS process. The post-process contained two main steps. One etched the sacrificial layer to expose the interdigitated electrodes, and the other coated the titanium dioxide film on the interdigitated electrodes.

Figure 6. Fabrication process of the integrated humidity sensor: (a) after the CMOS process; (b) etching the sacrificial layer; (c) coating the sensitive film.

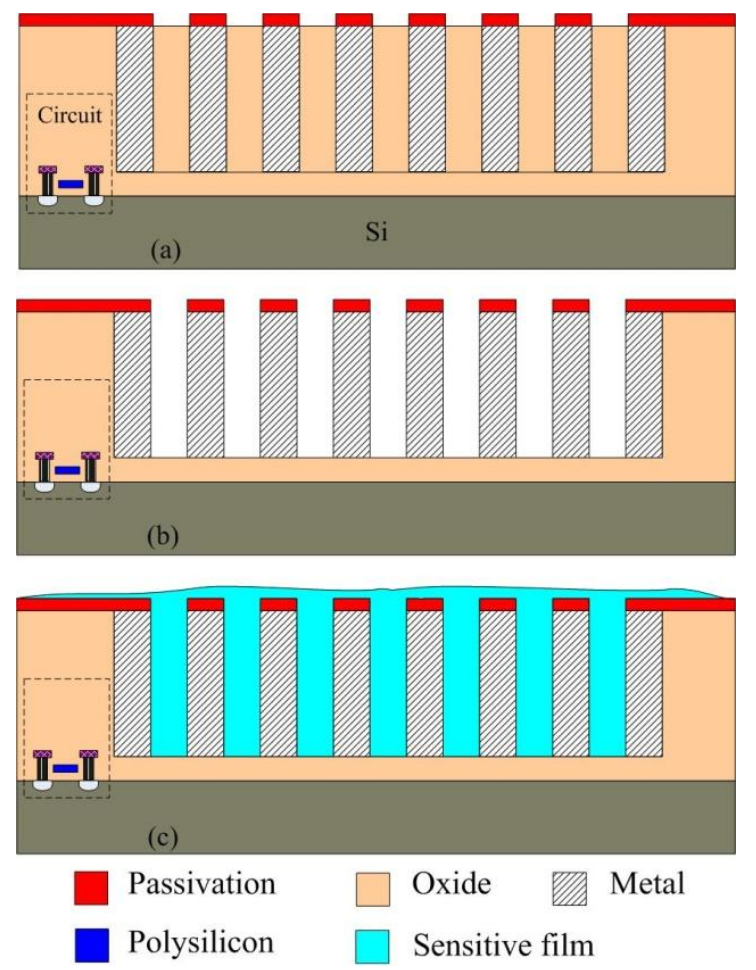

Figure 6a shows the cross-sectional view of the integrated humidity sensor after completion of the CMOS process. The interdigitated electrodes were made by the metal layers. Silicon dioxide located between the interdigitated electrodes was the sacrificial layer in which it needed to be removed. Figure $6 \mathrm{~b}$ shows that the sacrificial oxide layer was removed. The sacrificial oxide layer was etched by a wet etching with buffer oxide etch (BOE) etchant [28,29], to expose the interdigitated electrodes. Figure 7 shows a SEM image of the integrated humidity sensor after the wet etching. The metal of the interdigitated electrodes was an aluminum alloy. The melting temperature of the metal was about $450{ }^{\circ} \mathrm{C}$. Figure 8 shows a SEM image of the interdigitated electrodes after the wet etching. The interdigitated electrodes were fabricated completely. Figure $6 \mathrm{c}$ shows that the sensitive film was coated. A precision-control micro-dropper was used to drop the titanium dioxide onto the interdigitated electrodes, and then the titanium dioxide film was calcinated at $400{ }^{\circ} \mathrm{C}$ for $1 \mathrm{~h}$. Figure 9 presents an optical image of the integrated humidity sensor after the post-process. 
Figure 7. SEM images of the integrated humidity sensor after the wet etching.

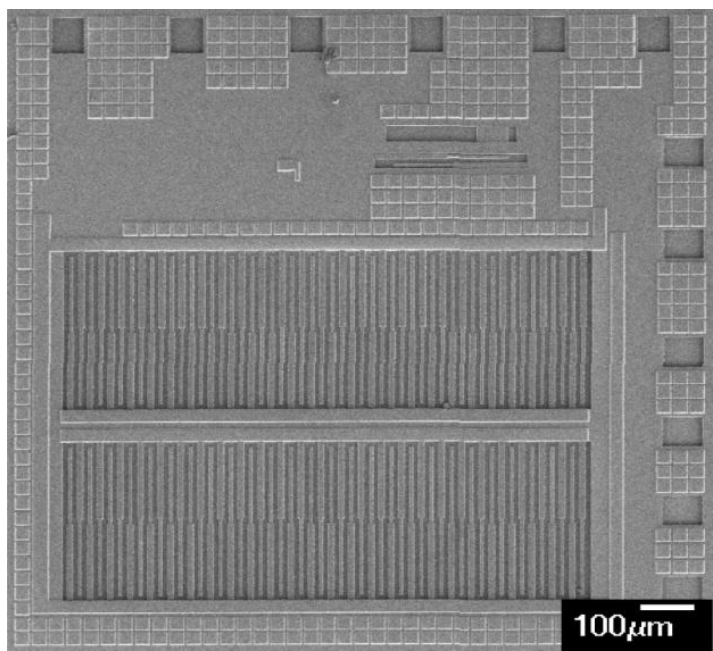

Figure 8. SEM image of the interdigitated electrodes.

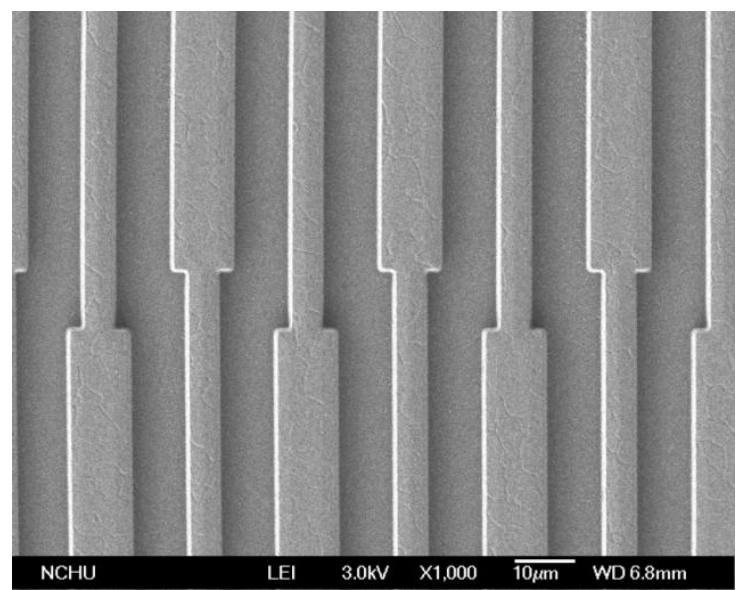

Figure 9. Optical image of the integrated humidity sensor after the post-process.

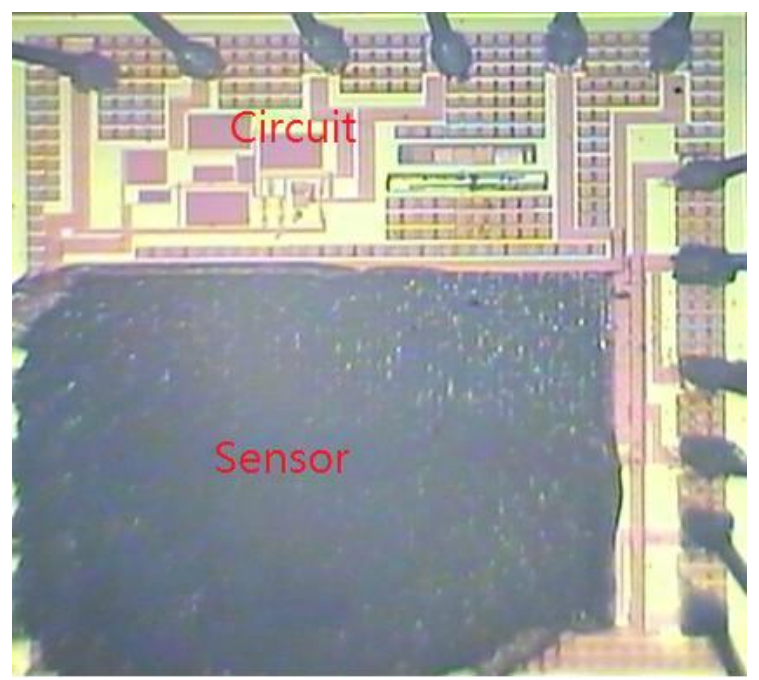




\section{Results and Discussion}

The performances of the humidity microsensor were tested by a power supply, a test chamber (GTH-099-40-1P, Giant Force Instruments Enterprise Co., New Taipei, Taiwan), a LCR meter and an oscilloscope. The test chamber could supply a humidity range of $25-90 \mathrm{RH} \%$ and a temperature range of $0-100{ }^{\circ} \mathrm{C}$. Temperature and humidity in the test chamber could be tuned separately and maintained at constant levels. The power supply was used to provide the bias voltage and the input voltage to the readout circuit.

The humidity sensor without readout circuit was tested in order to characterize the resistance variation of the sensor. The humidity sensor without readout circuit was set in the test chamber, and its resistance variation under different humidity was measured by the LCR meter. Figure 10 shows the resistance variation of the humidity sensor under different humidity conditions. The measured results revealed that the resistance of the humidity sensor changed from 72 to $240 \mathrm{k} \Omega$ as the humidity varied from 90 to $30 \mathrm{RH} \%$. The humidity sensor had a response time of $58 \mathrm{~s}$ and a recovery time of $65 \mathrm{~s}$.

Figure 10. Resistance variation of the humidity sensor without readout circuit at $25{ }^{\circ} \mathrm{C}$.

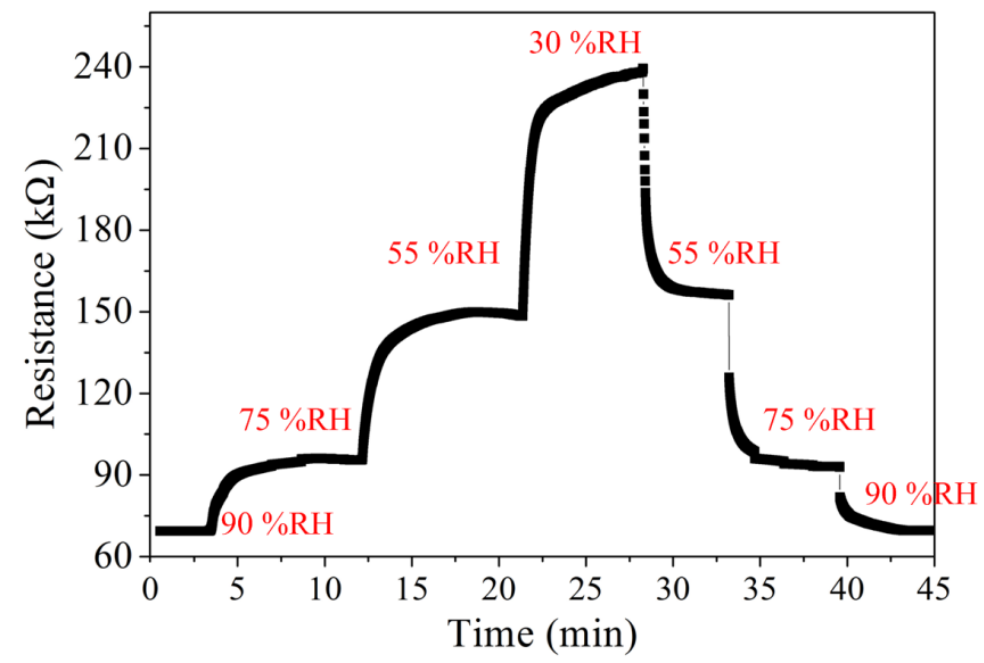

The humidity sensor with readout circuit was set in the test chamber. The test chamber provided different humidity levels to the humidity sensor. When the humidity in the test chamber rose or dropped, the resistance of the humidity sensor produced a change. The readout circuit converted the resistance variation of the sensor into the output voltage, and the oscilloscope recorded the output voltage. Figure 11 shows the measured results of the humidity sensor. In this measurement, the temperature maintained constant at $25{ }^{\circ} \mathrm{C}$ and the humidity varied from 30 to $90 \mathrm{RH} \%$ in $40 \mathrm{~min}$ and then dehumidified to $30 \mathrm{RH} \%$ at the same rate. The measured results showed that the output voltage of the humidity sensor changed from 2.27 to $2.05 \mathrm{~V}$ as the humidity increased from 30 to $90 \mathrm{RH} \%$.

To characterize the influence of temperature, the humidity sensor was measured under different temperatures. The output voltage of the humidity sensor was detected at different temperatures. Figure 12 shows the measured results of output voltage for the humidity sensor at different temperatures. The output voltage of the humidity sensor changed from 2.27 to $2.05 \mathrm{~V}$ at the temperature of $25{ }^{\circ} \mathrm{C}$ as the humidity increased from 30 to $90 \mathrm{RH} \%$. The output voltage of the sensor varied from 2.36 to $2.14 \mathrm{~V}$ at 
$55{ }^{\circ} \mathrm{C}$ as the humidity increased from 30 to $90 \mathrm{RH} \%$. As shown in Figure 12, the curves approach linearity in the range of 45-90 RH\%. According to the data in Figure 12, the relationship between the sensitivity and temperature for the humidity sensor can be obtained. Figure 13 shows the relationship between sensitivity and temperature for the humidity sensor. The results showed that the humidity sensor had a sensitivity of $4.5 \mathrm{mV} / \mathrm{RH} \%$ at $25{ }^{\circ} \mathrm{C}$ and a sensitivity of $4.8 \mathrm{mV} / \mathrm{RH} \%$ at $55{ }^{\circ} \mathrm{C}$. The sensitivity of the sensor increased as the temperature increased. As shown in Figure 13, the curve is a nonlinear. The ratio of sensitivity to temperature was $0.18 \mathrm{mV} / \mathrm{RH} \% /{ }^{\circ} \mathrm{C}$ in the temperature range of $25-35{ }^{\circ} \mathrm{C}$, and the ratio of sensitivity to temperature was $0.024 \mathrm{mV} / \mathrm{RH} \% /{ }^{\circ} \mathrm{C}$ in the temperature range of $35-55^{\circ} \mathrm{C}$.

Figure 11. Measured results of the humidity sensor at $25^{\circ} \mathrm{C}$.

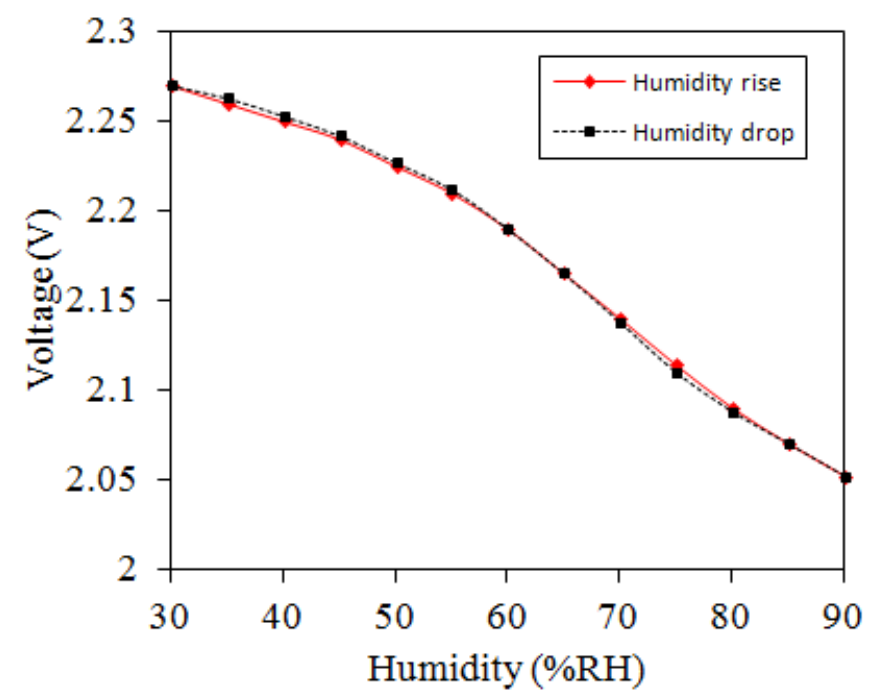

Figure 12. Measured results of the humidity sensor at different temperatures.

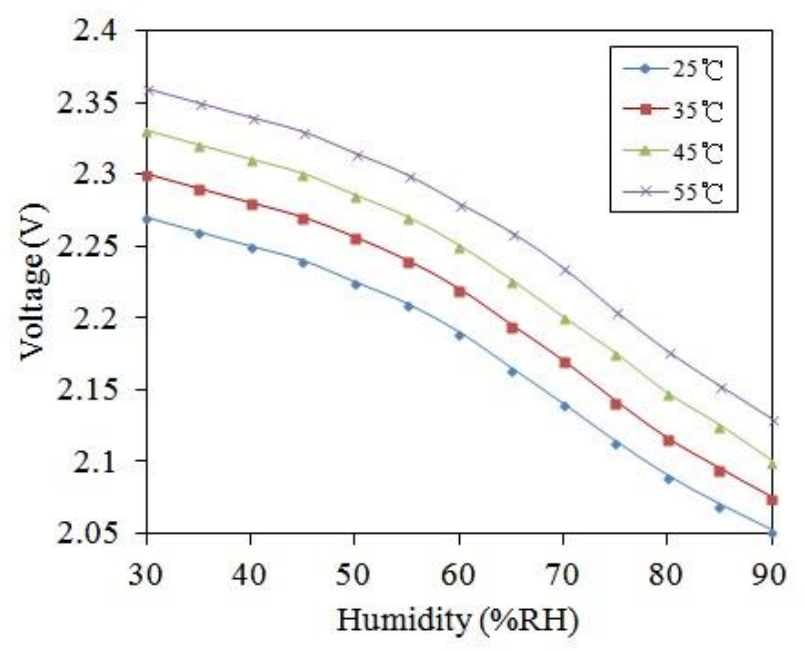


Figure 13. Relationship between sensitivity and temperature for the humidity sensor.

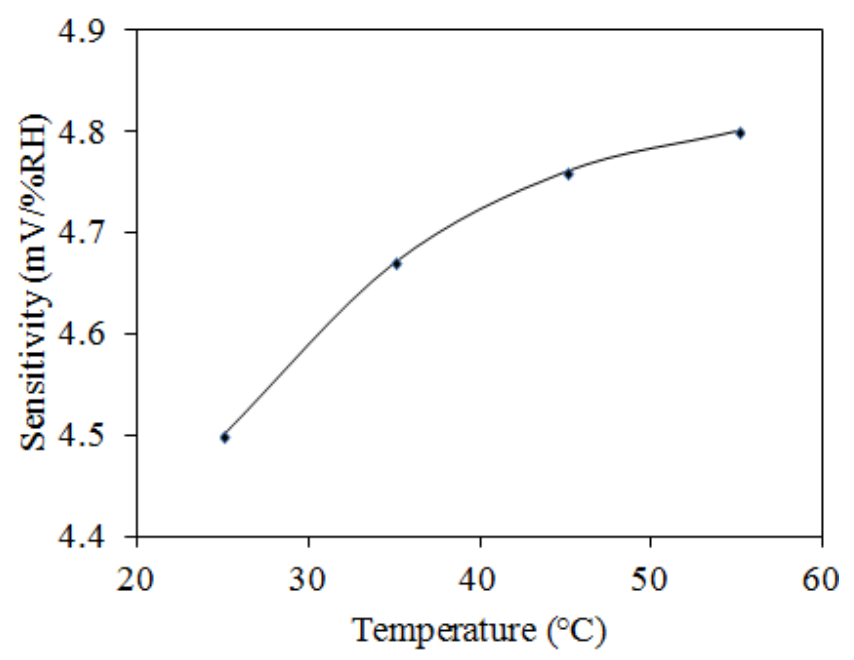

\section{Conclusions}

A humidity sensor equipped with a readout circuit was successfully manufactured using the commercial $0.18 \mu \mathrm{m}$ CMOS process and a post-process. The post-process was compatible with the commercial CMOS process. The humidity sensor consisted of a sensitive film and interdigitated electrodes. The sensitive film of the humidity sensor was titanium dioxide that was prepared by the sol-gel method. The titanium dioxide was deposited on the interdigitated electrodes. The humidity sensor generated a change in resistance as the sensitive film absorbed or desorbed water vapor. The resistance variation of the sensor was converted by the readout circuit into the output voltage. The sensor integrated with readout circuit on-a-chip would reduce noise and interference. The experiments showed that the output voltage of the humidity sensor decreased from 2.27 to $2.05 \mathrm{~V}$ as the humidity changed from 30 to $90 \mathrm{RH} \%$ at $25^{\circ} \mathrm{C}$. The humidity sensor had a sensitivity of $4.5 \mathrm{mV} / \mathrm{RH} \%$ at room temperature.

\section{Acknowledgements}

The authors would like to thank National Center for High-performance Computing (NCHC) for chip simulation, National Chip Implementation Center (CIC) for chip fabrication and the National Science Council of the Republic of China for financially supporting this research under Contract No. NSC 101-2221-E-005-007-MY3.

\section{Author Contributions}

$\mathrm{Yu}-\mathrm{Chih} \mathrm{Hu}$ carried out the design and fabrication of the titanium dioxide nanoparticle humidity sensors and measured their characterization. Ching-Liang Dai supervised the work of Yu-Chih Hu and wrote the paper. Cheng-Chih Hsu designed the readout circuit for the sensors. All authors read and approved the final manuscript.

\section{Conflicts of Interest}

The authors declare no conflict of interest. 


\section{References}

1. Gardner, J.W.; Varadan, V.K.; Awadelkarim, O.O. Microsensors MEMS and Smart Devices; Jon Wiley \& Son Ltd.: Chichester, UK, 2001.

2. Chen, L.P.; Zhang, J. Capacitive humidity sensors based on the dielectrophoretically manipulated ZnO nanorods. Sens. Actuators A 2012, 178, 88-93.

3. Kim, J.H.; Moon, B.M.; Hong, S.M. Capacitive humidity sensors based on a newly designed interdigitated electrode structure. Microsyst. Technol. 2012, 18, 31-35.

4. Lee, S.P. Response improvement of integrated humidity sensors using a micropump. Electron. Mater. Lett. 2010, 6, 215-220.

5. Lee, M.J.; Kim, J.S.; Kwak, K.Y.; Min, N.K. Micromachining of multilayer thin films for high-speed humidity sensor fabrication. Jpn. J. Appl. Phys. 2009, 48, doi:10.1143/JJAP.48.08HG01.

6. Chen, Q.; Fang, J.; Ji, H.F.; Varahramyan, K. Micromachined $\mathrm{SiO}_{2}$ microcantilever for high sensitive moisture sensor. Microsyst. Technol. 2008, 14, 739-746.

7. Su, P.G.; Ho, C.J.; Sun, Y.L.; Chen, I.C. A micromachined resistive-type humidity sensor with a composite material as sensitive film. Sens. Actuators B 2006, 113, 837-842.

8. Lazarus, N.; Fedder, G.K. Designing a robust high-speed CMOS-MEMS capacitive humidity sensor. J. Micromech. Microeng. 2012, 22, 085021.

9. Zhao, C.L.; Qin, M.; Huang, Q.A. A fully packaged CMOS interdigital capacitive humidity sensor with polysilicon heaters. IEEE Sens. J. 2011, 11, 2986-2992.

10. Yang, M.Z.; Dai, C.L.; Lin, W.Y. Fabrication and characterization of polyaniline/PVA humidity microsensors. Sensors 2011, 11, 8143-8151.

11. Dai, C.L.; Chen, J.H. Low voltage actuated RF micromechanical switches fabricated using COMS-MEMS technique. Microsyst. Technol. 2006, 12, 1143-1151.

12. Dai, C.L.; Chen, H.L.; Chang, P.Z. Fabrication of a micromachanied optical modulator using the CMOS process. J. Micromech. Microeng. 2001, 11, 612-615.

13. Dai, C.L.; Tsai, C.H. Fabrication of the integrated chip with microinductors and micro-tunable capacitors by complementary metal-oxide-semiconductor postprocess. Jpn. J. Appl. Phys. 2005, 44, 2030-2036.

14. Kao, P.H.; Shin, P.J.; Dai, C.L.; Liu, M.C. Fabrication and characterization of CMOS-MEMS thermoelectric micro generators. Sensors 2010, 10, 1315-1325.

15. Dai, C.L.; Lu, P.W.; Chang, C.; Liu, C.Y. Capative micro pressure sensor integrated with a ring oscillator circuit on chip. Sensors 2009, 9, 10158-10170.

16. Dai, C.L.; Tai, Y.W.; Kao, P.H. Modeling and fabrication of micro FET pressure sensor with circui. Sensors 2007, 7, 3386-3398.

17. Dai, C.L.; Kou, C.H.; Chiang, M.C. Microelectromechanical resonator manufactured using CMOS-MEMS technique. Microelectron. J. 2007, 38, 672-677.

18. Yang, M.Z.; Dai, C.L.; Lu, D.H. Polypyrrole porous micro humidity sensor integrated with a ring oscillator circuit on chip. Sensors 2010, 10, 10095-10104.

19. Dai, C.L.; Hsu, H.M.; Tai, M.C.; Hsieh, M.M.; Chang, M.W. Modeling and fabrication of a microelectromechanical microwave switch. Microelectron. J. 2007, 38, 519-524. 
20. Dai, C.L.; Chiou, J.H.; Lu, M.S.C. A maskless post-CMOS bulk micromachining process and its appliction. J. Micromech. Microeng. 2005, 15, 2366-2371.

21. Dai, C.L.; Yu, W.C. A micromachined tunable resonator fabricated by the CMOS post-process of etching silicon dioxide. Microsyst. Technol. 2006, 12, 766-772.

22. Onal, I.; Soyer, S.; Senkan, S. Adsorption of water and ammonia on $\mathrm{TiO}_{2}$-anatase cluster models. Surf. Sci. 2006, 600, 2457-2469.

23. Uchikawa, F.; Shimamoto, K. Time variability of surface ionic conduction on humidity-sensitive $\mathrm{SiO}_{2}$ films. Am. Ceram. Soc. Bull. 1985, 64, 1137-1141.

24. Sedra, A.S.; Smith, K.C. Microelectronic Circuits; Oxford: New York, NY, USA, 1998.

25. Wang, Z.Y.; Shi, L.Y.; Wu, F.Q.; Yuan, S.A.; Zhao, Y.; Zhang, M.H. The sol-gel template synthesis of porous $\mathrm{TiO}_{2}$ for a high performance humidity sensor. Nanotechnology 2011, 22, 275502.

26. Sadek, A.Z.; Partridge, J.G.; McCulloch, D.G.; Li, Y.X.; Yu, X.F.; Wlodarski, W.; Kalantar-zadeh, K. Nanoporous $\mathrm{TiO}_{2}$ thin film based conductometric $\mathrm{H}_{2}$ sensor. Thin Solid Films 2009, 518, 1294-1298.

27. Dai, C.L.; Chen, Y.L. Modeling and manufacturing of micromechanical RF switch with inductors. Sensors 2007, 7, 2660-2670.

28. Dai, C.L.; Peng, H.J.; Liu, M.C.; Wu, C.C.; Hsu, H.M.; Yang, L.J. A micromachined microwave switch fabricated by the complementary metal oxide semiconductor post-process of etching silicon dioxide. Jpn. J. Appl. Phys. 2005, 44, 6804-6809.

29. Dai, C.L. In situ electrostatic microactuators for measuring the Young's modulus of CMOS thin films. J. Micromech. Microeng. 2003, 13, 563-567.

(C) 2014 by the authors; licensee MDPI, Basel, Switzerland. This article is an open access article distributed under the terms and conditions of the Creative Commons Attribution license (http://creativecommons.org/licenses/by/3.0/). 